\title{
Identifying supportive daytime lighting characteristics for enhancing individuals' psychophysiological wellbeing in windowless workshop in tropical Malaysia
}

\begin{abstract}
Inappropriate architectural lighting exposures in workplaces are causing light-induced health and performance-related problems among healthy, urban individuals. This paper presents part one of an integrated tropical architectural lighting design framework for improving dayshift individuals' psychophysiological wellbeing in windowless workplace in Malaysia. The paper discusses five architectural lighting factors, namely intensity, spectrum, timing, duration, spatial distribution. The daytime lighting characteristics that influence individuals' psychophysiological wellbeing indicators (IPWI) were analysed. Findings indicated a dearth of literature in the lighting characteristics to support IPWI in the tropics, as evidence was predominantly from seasonal climate contexts. This motivated a critical discussion on the lighting factors and recommendations of alternative design consideration for a tropical Asian context. Potential daytime architectural lighting characteristics likely to support dayshift IPWI in windowless workplace in tropical Malaysia were also recommended for further investigations. These recommendations in the framework are expected to facilitate healthier windowless workplace design in Malaysia.
\end{abstract}

Keyword: Built environment informatics; Healthy workplace design; Lighting psychophysiological wellbeing; Sustainable tropical design windowless workplace 